\title{
Ishraq: Safe spaces to learn, play and grow: Expansion of recreational sports program for adolescent rural girls in Egypt
}

Nadia Zibani

Population Council

Follow this and additional works at: https://knowledgecommons.popcouncil.org/departments_sbsr-pgy

Part of the Family, Life Course, and Society Commons, Gender and Sexuality Commons, and the International Public Health Commons

How does access to this work benefit you? Let us know!

\section{Recommended Citation}

Zibani, Nadia. 2004. "Ishraq: Safe spaces to learn, play and grow: Expansion of recreational sports program for adolescent rural girls in Egypt," Ishraq: Safe Spaces for Girls to Learn, Play and Grow, Program Document. Cairo: Population Council. 
ISHRAQ: SAFE SPaces For Girls to Learn, Play and Grow

EXPANSION OF RECREATIONAL SPORTS PROGRAM FOR ADOLESCENT RURAL GIRLS IN EGYPT
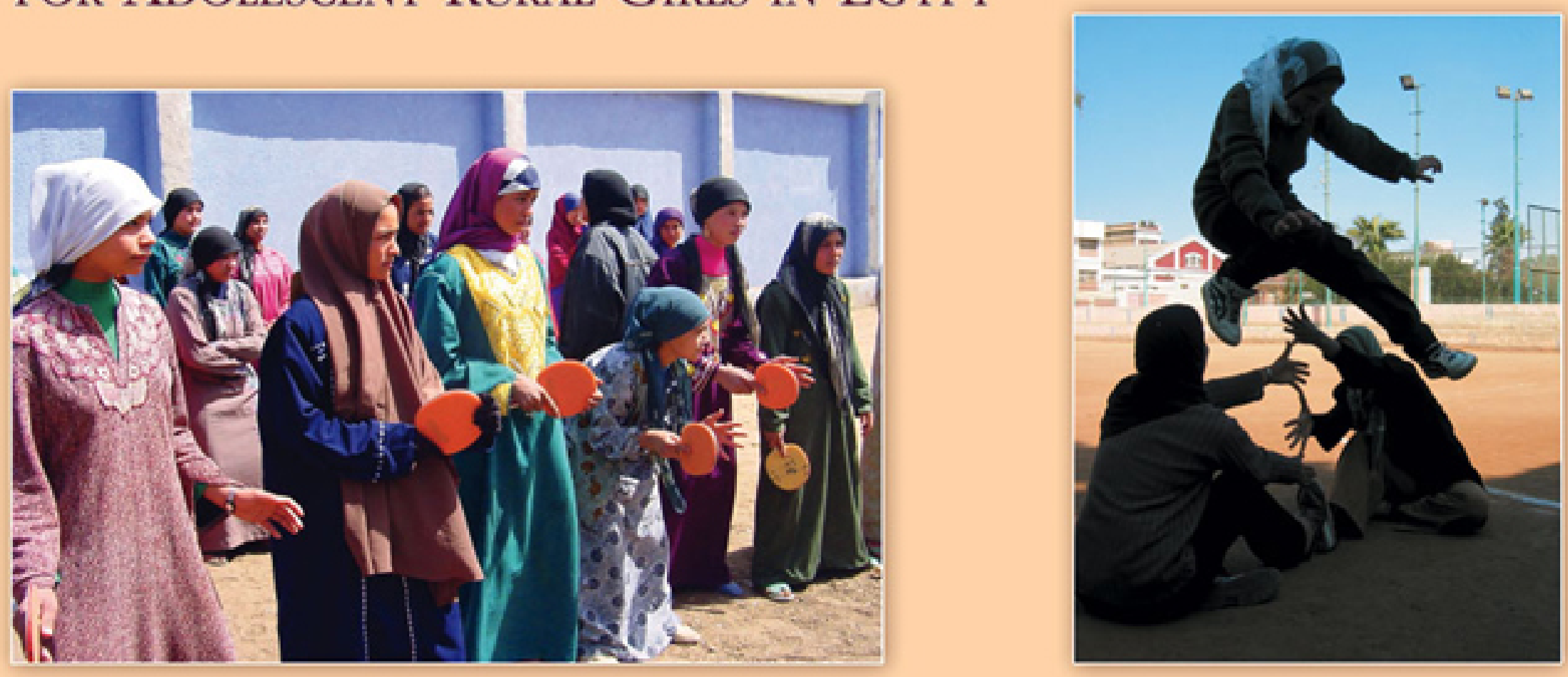

NADIA ZIBANI

A Population Council 


\section{ISHRAQ: SAFE SPACES FOR GiRLS to LEARN, Play AND GROW}

\section{PROGRAM DOCUMENT}

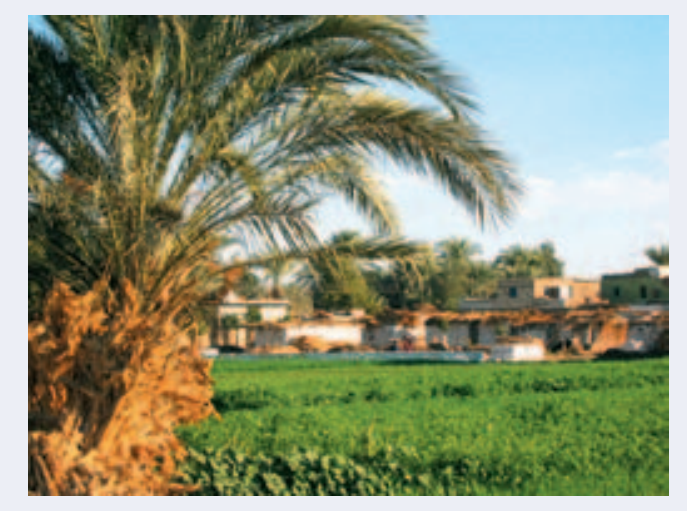

NADIA ZIBANI

(2) Population Council

REGIONAL OFFICE FOR WEST ASIA \& NORTH AFRICA GENDER, FAMILY, AND DEVELOPMENT PROGRAM 
Published by

\title{
(2) Population Council
}

The Population Council seeks to improve the well-being and reproductive health of current and future generations around the world to help achieve a humane, equitable, and sustainable balance between people and resources. The Council, a nonprofit, non-governmental research organization established in 1952, has a multinational board of trustees; its New York headquarters support a global network of regional and country offices.

\section{(C) 2004 Population Council}

For further information and copies please write to:

\author{
Population Council \\ Regional Office for West Asia and North Africa \\ 59, Misr-Helwan Agricultural Road, Maadi, Egypt. \\ Tel: (202) 525-5965/525-5967/525-5968 \\ Fax: (202) 525-5962 \\ Email:pcouncil@pccairo.org
}

NADIA ZIBANI is research coordinator with the Gender, Family, and Development Program, Population Council, West Asia and North Africa Office, Cairo.

Photographs courtesy of Nadia Zibani. 


\section{ACKNOWLEDGMENTS}

This document is the outcome of a collaborative effort with the International Table Tennis Federation (ITTF) Coordinator for ISHRAQ, Sanya El Aroussy. Several brainstorming sessions were held to share views on alternative teaching methods and their related resource implications. The most workable scenario has been presented in this document. It will, no doubt, contribute significantly to the success of this pioneering recreational sports program in the Middle East.

The author would like to thank Martha Brady, Program Associate at the Population Council's International Program in New-York, for offering her invaluable experience and insight with regard to promoting sports among girls in developing countries.

The author would also like to thank Moushira Elgeziri and Mei Elansary for reviewing this document. 


\section{PREFACE}

Over the past three years, I have observed the ISHRAQ program as it grew from a novel idea into a vibrant reality in the villages of northern El-Minya. In the process, approximately 300 rural girls have participated in a lifetransforming chance to learn, play, and grow into productive members of their local communities. Currently other villages - and soon other governorates - are joining the expanding ISHRAQ network in Egypt.

What makes ISHRAQ unique is its mixture of literacy, life skills training, and - for girls who have been sheltered in domestic situations of poverty and isolation - a chance to play sports and games with other girls their age. The very act of putting on a training suit and moving freely is new and exhilarating. The chance to learn physical skills and play on a team stretches these girls' sense of self worth and mastery; it reinforces the lessons they receive in life skills classes about hygiene, nutrition, and healthy living. Visiting the local youth center regularly opens doors of community participation to otherwise homebound girls. All of this is possible because the ISHRAQ leaders work carefully with parents and the community to reassure them and to provide safe, protected spaces for the girls to play.

We at the Population Council are pleased to present one of the fruits of the ISHRAQ pilot phase: a guide to the sports and games component of the program, geared to the needs of disadvantaged adolescent girls. It is intended for those in the development community interested in the potential of sports to enhance overall impact of adolescent programs. Sports can be readily combined with other program components to give girls a more active experience, whether the primary focus is reproductive health, literacy, or livelihood skills.

It is our hope that playing sports as teenage girls will set in place lifelong habits of physical activity and participation in civic life. ISHRAQ has demonstrated that engaging girls in programs they like and respect can make a real difference in their lives.

Dr. Barbara Ibrahim

Regional Director for West Asia and North Africa, Population Council 


\section{BACKGROUND ON THE ISHRAQ PROJECT}

In August 2001, the Population Council and Save the Children, in collaboration with the Center for Development and Population Activities (CEDPA), and Caritas launched the ISHRAQ ${ }^{1}$ project: Safe Spaces for Girls to Learn, Play, and Grow, a pioneering and comprehensive intervention to empower a generation of out-of-school girls. The three main components of this intervention are literacy, life skills, and sports. This intervention was first piloted in four rural villages in the Upper Egyptian governorate of El-Minya and targeted 278 girls aged 13-15 years.

The ISHRAQ program aims at supporting disadvantaged rural girls in their transition towards a healthy and active adulthood, and preparing them to make informed, positive decisions about life issues such as schooling, marriage, and careers. Today, three years later, the successful ISHRAQ pilot project is about to expand to target a larger population in three Upper-Egyptian governorates.

\section{BRIEF DESCRIPTION OF THEISHRAQ EXPANSION}

In January 2004, the ISHRAQ partners signed a Memorandum of Understanding (MOU) with the Egyptian Ministry of Youth and Sports (MOYS). According to this MOU, the Ministry will be responsible for assigning youth centers in participating villages to be part of the scale-up of the ISHRAQ program. More specifically, the Ministry will allocate within each youth center the necessary space, time, staff, and equipment - when available - for program implementation.

\footnotetext{
${ }^{1}$ The program was dubbed "ISHRAQ" which in Arabic means enlightenment. The name was given by the girls themselves to connote its "brightening effect"
} on their lives. 


\section{GEOGRAPHICAL AREAS}

The three selected areas for ISHRAQ expansion program activities are in the governorates of:

- Beni-Suef

- El-Minya

- El-Fayoum

\section{TTME-FRAME}

The project will be implemented in two phases over 36 months.

\section{TARGEIED RURAL COMMUNITIES}

Youth centers, which normally exist in each village, will be used as vehicles for implementing the program's three components: literacy, life skills, and sports. Twenty villages will be targeted in each governorate in phase one, reaching approximately 50 girls in two classes per village. Sixty rural communities will be selected among Beni Suef's 220 existing villages, El-Fayoum's 159 villages, and El-Minya's 344 villages ${ }^{2}$. Participating villages in the three geographical areas should be selected using the following criteria:

1. High level of out-of-school girls

2. Existence of a youth center ${ }^{3}$

3. Activity of youth center, as per results of the inventory made on facilities and services provided 4. Proximity of villages ${ }^{4}$

\footnotetext{
${ }^{2}$ Information obtained in May 2004 from Observatoire Urbain du Caire Contemprorain (OUCC) at the centre d'Etudes et de Documentation Economiques et Juridiques (CEDEJ) in Cairo.

${ }^{3}$ In some cases, an exception may be considered when villages with no youth center express strong interest for the program.

${ }^{4}$ When selecting nearby rural communities, proximity will increase the chance of organizing sports tournaments between villages, making it easier for girls to travel. In addition, project management will become more cost effective because sports promoters will be able to cover more than one village at a time.
} 


\section{NUMBER OF SPORTS PROMOTERS}

To calculate the number of sports promoters required, an estimate of one for every two neighboring villages was used, ${ }^{5}$ bringing the number of sports promoters to 10 per governorate, with an extra five young women who may serve as substitutes for the program's three components.

\section{LESSONS LEARNED FROM PILOT PROJECT}

Unlike the literacy and life skills programs, the ISHRAQ sports component was an unprecedented intervention, with no comparable initiatives in Egypt to draw from. The pilot focused on four team sports (basketball, volleyball, handball, and football), with the aim of developing the girls' self-confidence, team spirit, negotiation skills, and leadership abilities. Reflection on program goals, a careful analysis of the status of beneficiaries at the end of the pilot project - in terms of skills and aquired sports-related knowledge, and sports trainers' opinions on sports - have shown that to achieve measurable results, a more pragmatic and less ambitious sports program is required. Accordingly, the number and type of sports have been revised. Instead of four different sports, two have been chosen for the new recreational sports program: one individual sport and one team-based sport. Depending on the "area of expertise" of both the recruited sports promoters and senior sports trainers, one of three combinations will be offered in the sports program: 1) table tennis and handball, 2) table tennis and basketball, or 3) table tennis and volleyball. ${ }^{6}$

\footnotetext{
${ }^{5}$ In selecting the villages, it is crucial to map and verify the distance between them.

${ }^{6}$ For conservative and traditional settings, it is probably safer to remove football as an option for many reasons including its masculine nature and the ensuing resistance from parents to their daughters' particpation in this sport. "When we used to play football in the program, people said that we (girls) were like boys," said an ISHRAQ participant.
} 


\section{EXPANDED RECREATIONAL SPORTS PROGRAM OBJECTIVES}

ISHRAQ recreational sports program is designed to ensure that participating girls:

】 Have fun in a safe and activity-based environment;

】 Enhance feelings of self-worth and self-confidence;

- Acquire skills in a wide range of recreational activities;

v Learn information and attitudes to help them live safer lives;

\ Maintain mental and physical health;

\ Develop lasting friendships.

This innovative program targets out-of-school adolescent girls between the ages of 11 and 15 who live in disadvantaged and highly conservative Egyptian rural communities. A variety of sports-related and recreational game sessions revolving around basic health and hygiene-type information, and individual and team activities will be offered. Activities will include relays, friendly competitions, and more.

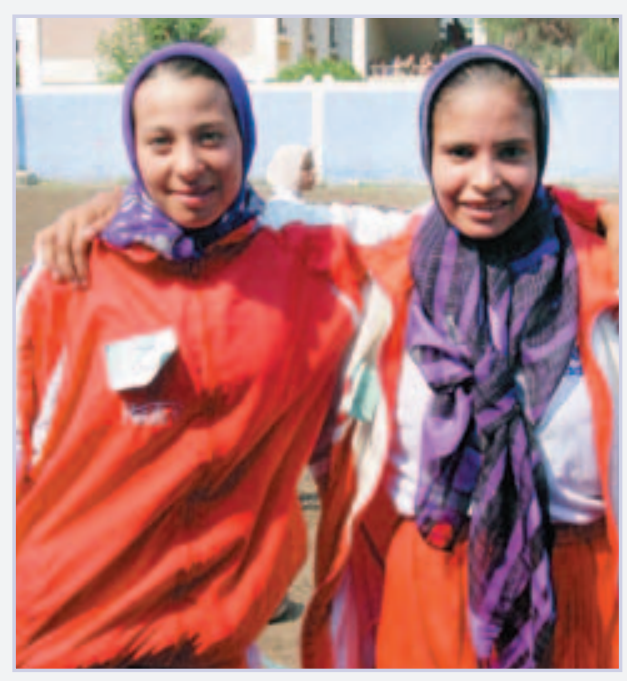

\section{SCHEDULE}

\section{TTME OF DAY}

Whenever possible, sports sessions will be scheduled first thing in the morning to avoid hot weather and promote a girl-friendly environment, as males are usually more present at the youth centers in the afternoon. 


\section{WEEKLY TIME TABLE}

Recreational sports sessions will take place twice a week at youth centers in participating communities. ${ }^{7}$ Each sports session will be an hour and a half long. During the first half-hour, various sports-related information will be taught, after which organized sports, games, and related activities will be offered. Locally recruited female sports promoters will supervise all activities. During breaks, participants will be encouraged to drink fluids and have a snack.

\section{PARENTAL SUPPORT}

Apprehension expressed by parents and other family members may be dealt with by finding appropriate roles for them to play, in a voluntary capacity, to support the program. For example, participants' mothers can take turns providing snacks and organizing break-time activities.

\section{ELGIBLE BENEFICIARIES: ADOLESCENT GIRLS}

In traditional agricultural communities, families are often highly patriarchal and tend to hold a strong preference for sons. A male child is greatly valued and often receives more investments from the family. For rural, out-ofschool girls, discrimination is therefore an everyday experience that is demonstrated in the low priority given to their education, health care, and individual rights.

Introducing the concept of sports for adolescent girls in such a context is thus an unprecedented challenge, given restrictive gender norms and the resulting belief that sport is a superfluous, unfeminine activity.

${ }^{7}$ When selecting the days, we need to make sure that they are not conflicting with other schedules such as "market day" or "baking day." 
To successfully implement a girl-friendly recreational sports program, it is essential to:

1. Ensure early on that participants' parents and the community at large have a good understanding of the sports program;

2. Target an age bracket that is not too old to play - 11 to 15 years may be ideal;

3. Select times and days of play in collaboration with participants;

4. Choose a facility that is within walking distance from their homes;

5. Ensure that girls feel safe from the fear of being watched or harassed by boys and men, thereby protecting their dignity and reputation;

6. In conservative settings, ensure that girls play only with girls, at least in the beginning;

7. Select locally recruited young women to serve as sports promoters to deliver the sports activities;

8. Introduce sports in a friendly, non-threatening environment and keep the program simple.

\section{SPORTS PROMOTERS AND TRAINING}

The recreational sports program will rely on "sports promoters" to act as agents advocating sports and transferring relevant skills to program participants. Given the pioneering nature of the ISHRAQ sports program and the importance of its sustainability, the task of identifying appropriate sports promoters, especially for rural areas, is of paramount importance. 


\section{HOW TO FIND POTENTIAL SPORTS PROMOTERS (SPS)}

\section{1- FROM VILLAGES}

Ideal promoters are young educated females, between the ages of 18 and 25, who are interested in being active and in sports. They are screened and hired at the village level. When designing a sports program with novice sports promoters, it is crucial to have modest, realistic, and achievable goals .

\section{2- THROUGH SPORTS FEDERATIONS}

Names of local members of such sports federations as table tennis, volleyball, basketball, and handball, will be proposed as potential sports promoters. Unlike the above group, local federation members have already acquired the basics in their selected sport, having played on local teams. It is anticipated, however, that not all three governorates will have candidates from the same sport. In such a case, it may be appropriate to allow for different sports in different governorates, based on the strength of the local human resources available there. As such, the program must be flexible enough to accommodate basketball in one governorate and handball in another, for example, with table tennis offered in all three governorates.

\section{IDEAL SPS CANDIDATE PROFILE}

- $\quad$ Positive attitude

- Pleasant, extroverted nature

- Good communicator

- Leadership qualities

- Problem-solving skills
- Physically fit

- Sensitive to and respectful of the girls and their parents

- Observant and good listener

- Organized

- Fair 


\section{TRAINING REQUIREMENTS}

Given the novelty of the "sports promoter" position, and the candidates' lack of experience, a series of sports training courses will be developed and offered both in the form of general physical fitness training and in sportspecific training. Athletes and other sports people enthusiasts from cities will be solicited to volunteer their time in the capacity of "senior sports trainers." In all instances, female recruits will be favored. Topics for sports promoters training will include, but are not limited to:

- Planning a sports session

- Setting achievable goals

- Introducing variety to keep the session interesting

- Teaching one skill at a time.

In all of the training offered, the importance of the following will be stressed:

- Providing clear, positive, and instant feedback

- Involving all participants in each activity

- Keeping the lesson simple

- Ensuring that participants listen, see, and practice at all times.

An ISHRAQ's Sports Curriculum for Rural Girls in Egypt has been developed, with simple easy-to-use guidelines on the basics of the sports selected. The sports curriculum includes sessions on the skills and drills required, strategies to be used, fitness exercises needed, as well as rules and regulations, and equipment specifications, where applicable. Prior to embarking on a specific sport, participants will need a friendly introduction to the fundamentals of sports and physical activity, never losing sight that the purpose of their involvement in a sport is essentially to "have fun" in an informal, non-competitive context. 
Using a participatory, interactive methodology, this tool provides age-specific information related to health, hygiene, and nutrition, in addition to a number of other topics directly related to rural adolescence. The approach emphasizes "learning by doing," which allows participants to work in small groups and learn by taking part in activities rather than by passively receiving information. To help girls learn to question and assess their options; set and achieve goals; and, most importantly, develop a sense of autonomy and self-confidence, program activities include role playing, initiative-taking drills, and a number of team-based games.

\section{SPORTS PROGRAM CONTENT}

A description of the 13-month implementation period of the sports program is presented below. It is envisaged that this implementation will be divided into three main phases: introductory, implementation, and monitoring and evaluation.

\section{INTRODUCTORY PHASE}

\section{Duration: Three Months}

It is anticipated that an introductory phase would be useful, first to make participants and parents more receptive to the sports program and, second to provide participants with a general introduction to physical activity, and expose them the benefits of fitness, a background on hygiene, nutrition, health, biology, and so forth.

From our experience in the pilot phase, it has become clear that the success of the recreational sports program will depend very much on the support demonstrated by both parents and brothers. Understanding, anticipating, and managing parents' concerns/worries around sports is critical to success. Without their approval, it is unlikely that girls will be able to participate. Accordingly, prior to program startup, the sports' component team members 
will organize a series of orientation meetings with parents and other key gatekeepers' (older brothers, uncles) at the village level. Two such meetings are outlined below:

Orientation Meeting 1: A meeting will be organized for the beneficiaries' parents and community at large to make sure that they have a good understanding of the recreational sports program, its philosophy, and goals.

Orientation Meetnng 2: Another meeting will be held to discuss challenges with parents and community leaders and help break down misconceptions around sports for girls by outlining the benefits of the sports program.

During this introductory phase, the ISHRAQ's three-month basic sports curriculum will deal with a series of basic sports-related information sessions that are outlined below. ${ }^{8}$ These sessions are followed by the proposed table tennis program.

\section{SPORTS-RELATED INFORMATION SESSIONS OUTUNE}

\section{EXPLORING FORMAT AND CONTENT OF A SPORTS SESSION WITH PARTICIPANTS}

- Introduce sports promoters and highlight responsibilities;

- Describe the format of a sport session;

- Define appropriate conduct;

- Highlight basics for correct sports practice and injury prevention.

\section{BECOMING A TEAM MEMBER IN ISHRAQ}

- To capture attendance and document absenteeism of sports sessions in a participatory manner.

\footnotetext{
${ }^{8}$ A recent sports guide entitled "ISHRAQ's Basic Sports Curriculum for Rural Girls in Egypt (Three-Month Introductory Phase)" was designed
} by Nadia Zibani (December 2004). 


\section{PARTICIPATING IN SPORTS: FACTS AND FALLACIES}

To breakdown misconceptions about girls and sports:

- Fallacy \# 1: Girls should not play like boys;

- Fallacy \# 2: Sport for girls is socially unacceptable "Eib";

- Fallacy \# 3: Girls are not strong enough to play sports like boys and are likely to get hurt;

- Fallacy \# 4: Girls don't play sports because they are afraid they won't be good at sports;

- Fallacy \# 5: Girls don't play sports because they are afraid of being teased;

- Fallacy \# 6: Girls don't play sports because they are afraid of being perceived as unfeminine;

- Fallacy \# 7: Girls don't play sports because they should not wear pants or track suits;

- Fallacy \# 8: Girls your age, are too old to play;

- Fallacy \# 9: Girls are too busy to play.

\section{INTRODUCING BASICS IN HYGIENE}

Provide basic information related to cleanliness:

- Body hygiene ${ }^{9}$;

- Eating habits;

- Drinking;

- Breathing and sweating;

- Appropriate clothing and footwear.

\footnotetext{
${ }^{9}$ It is very important to address issues of hygiene with great sensitivty and tact in order to avoid hurting people's feeling.
} 


\section{MAPPING YOUR COMMUNITY}

- Identify the various spots frequented by girls in their village, and determine which are socially acceptable for girls to visit;

- Explore different states/situations that make girls feel safe emotionally and/or physically;

- Discuss why youth centers are rarely a favored destination for girls.

DISCOVERING THE JOY OF MOVEMENT

- Define what it means to be physically fit;

- Encourage girls to demonstrate games from their childhood and to be more aware of their own physical ability;

- Learn their reasons for no longer participating in playing games.

INTRODUCING PHYSICAL FITNESS WITHIN THE CONTEXT OF TRADITIONAL GAMES

- Balance

- Flexibility

INTRODUCING PHYSICAL FITNESS WITHIN THE CONTEXT OF TRADITIONAL GAMES

- Coordination

- Speed/reflexes

INTRODUCING PHYSICAL FITNESS WITHIN THE CONTEXT OF TRADITIONAL GAMES

- Strength

- Cardiovascular endurance 


\section{HAVING A FEMALE ROLE MODEL}

- Elicit from participants role models within the community. Outline attributes of an "ideal" woman;

- Using magazines, photos, videos, etc. introduce several remarkable female athletes from the Arab world;

- Highlight their accomplishments and present the different challenges that they overcame;

- Examine the values associated with sport: fair play, sporting spirit, honesty, integrity, competitiveness towards excellence.

\section{ADVOCATING A SMOOTH TRANSITION INTO ADOLESCENCE}

- Review the physical changes related to puberty;

- Introduce weight bearing physical drills and stress the importance of such activity on a daily basis during adolescence.

\section{PROMOTING A POSITIVE SELF-IMAGE}

- Present a series of questions and hypotheses to help redress negative attitudes and feelings that participants may have about themselves;

- Ask participants to imagine themselves five years from now.

\section{EXERCISING AND THE BODY}

- Review heart and lung functions and describe physical changes that occur during exercise;

- Provide tips for a healthy sports session.

\section{MAINTAINING A HEALTHY DIET: DO'S AND DON'TS}

- List everything you ate yesterday;

- Review food pyramid, stressing importance of food as a source of energy;

- Provide tips for proper food intake and exercise. 
During this initial 12-week schedule, designed for beginners, a number of skills have been grouped within three categories based on their level of complication. The first basic category, entitled "BODY MOVEMENT," deals with skills that are used to move around with the body from one place to another. These include walking, running, shuffling, galloping, hopping, jumping, leaping, and skipping. The second category is entitled "AGILITY" and involves ways of changing direction when in motion. These include stopping and starting quickly, rapid change of direction, and bending or twisting to avoid a tag. The third category, entitled "PROP MANIPULATION," involves skills required for using and handling a variety of sports-related props, which include balls, skipping ropes, hula hoops, and dumbbells. Just like boys, girls need to develop the skills of throwing, catching, kicking, and dribbling in order to have fun and enjoy playing a team-based sport. To help girls learn the various above-mentioned basic skill sets, different exercise/practice opportunities in a fun, game-like setting are included in the ISHRAQ's Basic Sports Curriculum for Rural Girls in Egypt. By the end of the introductory phase, participants will have acquired skills like tossing, throwing overhead, kicking, volleying, striking, and passing, in addition to some basics in hitting with a racquet, which will allow for a smooth transition to the table tennis program, which will start in month four of program implementation.

\section{IMPLEMENTATION PHASE}

\section{Duration: Ten Months}

To encourage beneficiary participation, it is essential to offer an attractive program with interesting and stimulating activities. While designing the new ISHRAQ recreational sports program and planning activities, particular emphasis must be placed on the learning process and on access to basic health information, in addition to acquiring sports skills in a pleasant and friendly environment. Sports sessions will take place in youth centers, and girls will be provided with the appropriate clothing for physical activity. It is important to keep in mind that each participating girl needs to have something exciting to look forward to when taking part in different kinds of practice sessions. 
The implementation phase has been divided into four learning cycles, each lasting about two and a half months, at a rate of two one-and-a-half-hour sessions per week over a 10-week period. These cycles are:

$\neg$ CYCLE 1: BASICS IN SPORT

$\neg$ CYCLE 2: PRIMARY SKILLS

$\neg$ CYCLE 3: SKILL DEVELOPMENT

$\neg$ CYCLE 4: INTERMEDIATE LEVEL

During the first cycle, sessions will begin by focusing on basic sports-related information and general exercises. Then the basics of table tennis, the first organized sport in the program, will be introduced. During the second cycle, table tennis skills will begin to be acquired and the basics in the team sport of choice will be presented. Cycle three will be devoted to further developing table tennis skills along with acquiring team sports skills. By cycle four, participants should be able to reach a modest level of ability in both table tennis and the team sport offered in that governorate (See below Table 1).

TABLE 1: BREAKDOWN OF FOUR LEARNING CYCLES, (10 MONTHS)

\begin{tabular}{|l|l|c|c|}
\hline \multicolumn{1}{|c|}{ Cycles } & \multicolumn{1}{|c|}{ Topics } & $\begin{array}{c}\text { No. of sessions } \\
\text { (1.5 hrs each) }\end{array}$ & No. of Hours \\
\hline CYCLE 1: BASICS & Sessions 1-24 Plus Basics in Table Tennis & 24 & 30 \\
\hline CYCLE 2: PRIMARY SKILLS & $\begin{array}{l}\text { Primary skills in Table Tennis Plus } \\
\text { Basics in team sport of choice }\end{array}$ & 20 & 30 \\
\hline CYCLE 3: SKILL DEVELOPMENT & $\begin{array}{l}\text { Skill development in Table Tennis Plus } \\
\text { Primary skills in team sport of choice }\end{array}$ & 20 & 30 \\
\hline CYCLE 4: INTERMEDIATE LEVEL & $\begin{array}{l}\text { Intermediate level in TableTennis Plus } \\
\text { Skill development in team sport of choice }\end{array}$ & 20 & 30 \\
\hline
\end{tabular}




\section{TABLE TENNIS PROGRAM}

Table tennis is the first organized sport that sports promoters and participants will be trained in. The three reasons for this selection are: 1) the enormous success of the two introductory training courses in table tennis (as individual sport) made during the pilot phase; 2) the relative ease with which the sport can be played, "Every table is a table tennis table" and; 3 ) the commitment already demonstrated by the International Table Tennis Federation (ITTF) and the Egyptian Table Tennis Association (ETTA) in collaboration with the Egyptian Ministry of Youth and Sports. ${ }^{10}$

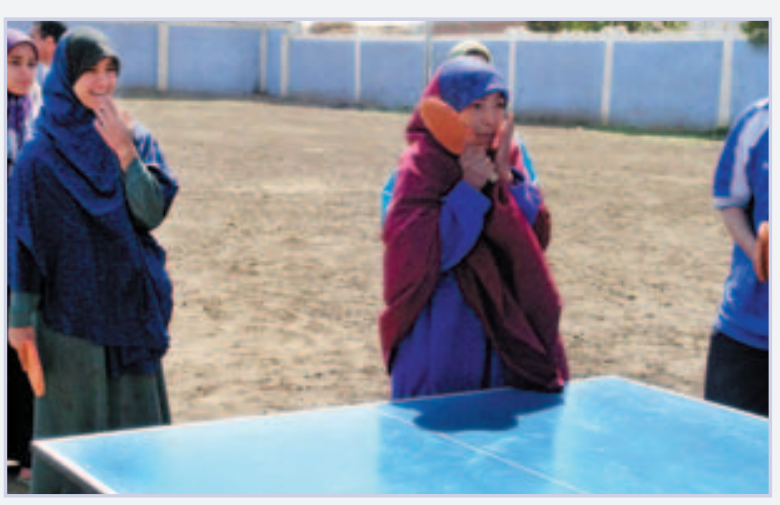

According to ITTF Development Manager, important reasons for incorporating table tennis in a sports program are:

- Table tennis (TT) provides a fun, inexpensive, and non-threatening exposure to sport;

- TT can be easily adapted to suit the rural communities;

- TT lessons for beginners are structured for "maximum activity with minimum equipment" with a focus on "fun, activity and learning;"

- $\quad$ TT is a "lifetime" sport activity that can be enjoyed from 4 to 90 years of age;

- $\quad$ TT can be played "socially" but always provides a clear elite pathway through to Olympic level for those motivated to do so;

- Competitions can be easily structured for maximum participation.

10 Through ETTA, Egypt's Minister of Youth and Sports has generously donated 30 table tennis to ISHRAQ. In March 2003, ITTF, with its Egyptian counterpart ETTA, offered a 3-day introductory training course to 20 classroom promoters and sports trainers (male and female). 
With their expertise and considerable developmental experience, ITTF and ETTA have developed table tennis training programs and will be providing technical assistance. Using ITTF's international program, "Breaking down barriers with table tennis balls," they will deliver a series of workshops that teach exercises and drills. The first session will be an intensive, two-week workshop entitled "Basics in Table Tennis" that will train the 45 sports promoters in the fundamentals of table tennis. A breakdown of the workshop topics is presented on the next page (See below Table 2). These training courses are designed for the new locally recruited sports promoters, who will in turn train the participants once they have acquired the basic skills themselves.

This sports program places greater importance on enjoyment of sport rather than attaining excellence. Priority is always given to participation in sport and to having fun. In the ISHRAQ pilot project, many girls expressed that "having fun" is their primary motivation. "Making friends" is another motive mentioned by most girls. Since this is their first experience with sports, the program begins by teaching the basics of a given sports activity so that participants can develop their skills and increase their confidence and interest in pursuing sports.

\section{TABLE 2: BREAKING DOWN BARRIERS WITH TABLE TENNIS BAШS: BASICS TRAINING COURSE}

- WHAT IS NEEDED?

- GETTING STARTED

- STARTED LESSON SUMMARY

- GRIPTABLE TENNIS RELAYS

- BOUNCER

- READY POSITION

- MIRROR FOOTWORK- FUN ACTIVITIES

- FOREHAND DRIVE- BACKHAND DRIVE- FOREHAND PUSH- BACKHAND PUSH

- ROUND THE TABLE

- SERVICE-RETURN OF SERVICE

- BEAT THE CHAMP

- PATHWAYS FOR OUR GIRLS

- IS YOUR LIFE IN A SPIN?

- ORGANIZING A TOURNAMENT

- CERTIFICATES

- FRIENDLY COMPETITION

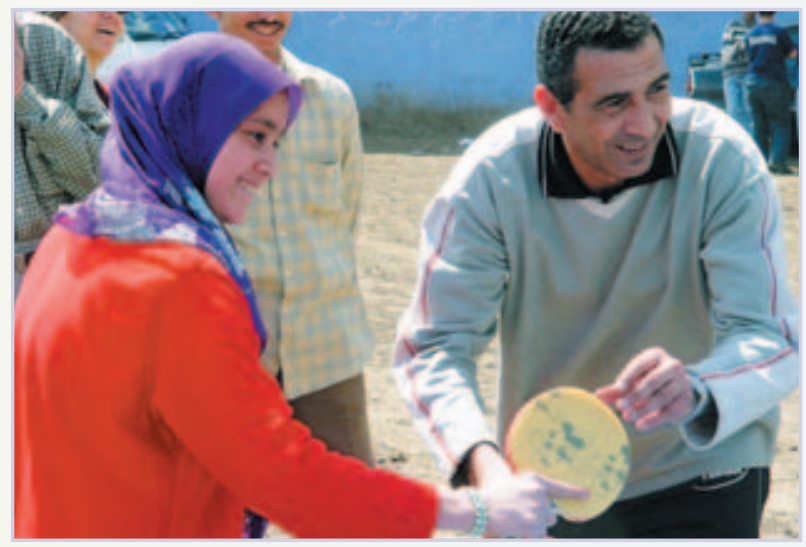


ETTA will assume the follow-up training for the remaining period of the project life. Every two months, a three-day course will be held for sports promoters to build acquired skills and introduce additional skills. By the end of the implementation phase, it is anticipated that both sports promoters and participants will have achieved a reasonable level of proficiency in the sport, advancing them from the novice category to that of the "seasoned" beginner.

We hope that after the 10-month period of playing table tennis, the girls will be "winners"!

- To have a better future;

- To believe in themselves;

- To continue their education;

- To have the strength to say "no way" to early marriage, and female genital mutilation (FGM).

\section{TEAM SPORTS PROGRAM}

For the second type of sport that will be offered to participants, the choice between basketball, volleyball, and handball will depend on the availability and experience/proficiency of both senior sports trainers and local members of their specific team sports, as well as their readiness to work in partnership with the ISHRAQ sports program.

In collaboration with the MOYS, we are contacting three Egyptian sports federations (basketball, handball, and volleyball) to discuss potential partnerships for providing technical assistance in delivering the ISHRAQ team sports. 


\section{MONITORING AND EVALUATION PHASE}

Over the course of the implementation period of the sports activities, we will need a monitoring system to provide us with feedback from participants, sports promoters, and others involved in the program. A feedback mechanism will allow us to learn from experience and revise the program as needed to accommodate community needs.

The evaluation of the sports program will examine three elements of the intervention: curriculum, community, and ISHRAQ ability. The curriculum monitoring for the sports program will examine the quality and usefulness of the training available to sports promoters. Information from sports promoters detailing the effectiveness of their training will be gathered to see if the training program needs to be revised.

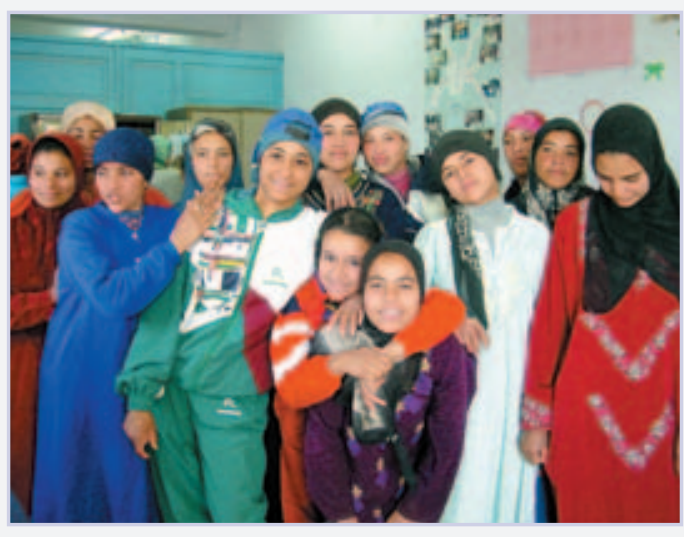

The ISHRAQ integrated learning and sports program is the first of its kind in the Middle East. Developing countries and their ministries of youth and sports may have policies that acknowledge equal rights, access, and opportunities for youth; however few of these policies are implemented in rural settings. Since the youth centers used for ISHRAQ are dominated by males both at the level of participation and of management, it will be interesting to learn how the ISHRAQ sports program has been integrated into youth center programming in rural communities. The evaluation will also assess the ways in which the equipment, provided by generous contribution from the sports federations, is being used in youth centers.

To date, considerable research has documented the links between girls' physical activity and positive health and social outcomes mostly in the United States and in other Western countries. However, in the developing world there are few studies on the impact of sports on young females. Thus an assessment of the impact the ISHRAQ sports component has had on girls in rural Egypt represents an important step in promoting the rights of girls and women to full participation in sports and physical education. We are also interested in learning about participants' experiences and perceptions regarding their participation in a sports program for the first time. 


\section{SPORTS MEDIA}

\section{DAI LY MARKET INTEU GENCE ON INTERNATIONALSPORTS TELEVISION AND MEDIA}

The International Table Tennis Federation's film Breaking Down Barriers with Table Tennis Balls produced in rural Egypt about the ISHRAQ project has been selected for presentation at the Sport Movies \& TV 2004 - 22nd International Festival to be held in Milan later this year ${ }^{11}$.

\section{Dear Friends,}

Some of you may have seen this film that was shown at the last ITTF Women's forum and in Marrakech at the 3rd IOC Women and Sport Conference (there were problems having it shown during my talk in Marrakech, but it was shown the next day) about the ISHRAQ program that the ITTF is involved in, in rural Egypt together with the Population Council and Save the Children. ISHRAQ involves young girls from rural Egypt who now have a chance to play table tennis and learn other life skills. The program is part of the ITTF development strategy known as "breaking down barriers with table tennis balls."

The film has been selected for presentation at the 22nd International Festival for sport movies and TV this year in Milan. I hope this gives the ISHRAQ program the visibility it deserves and helps us to generate similar projects for girls and women in other parts of the world.

Best regards,

$L$ ila de $S$ oysa

ITTF Project Manager

\footnotetext{
${ }^{11}$ It may be seen at www.popcouncil.org/me/middle_east.html.
} 


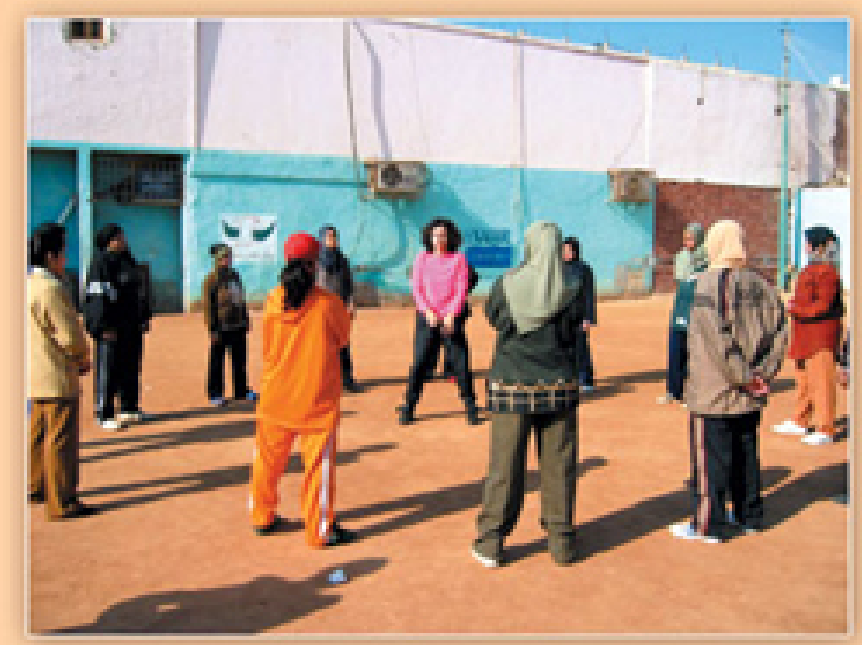

\section{LEARN}

\section{GROW}

PLAY

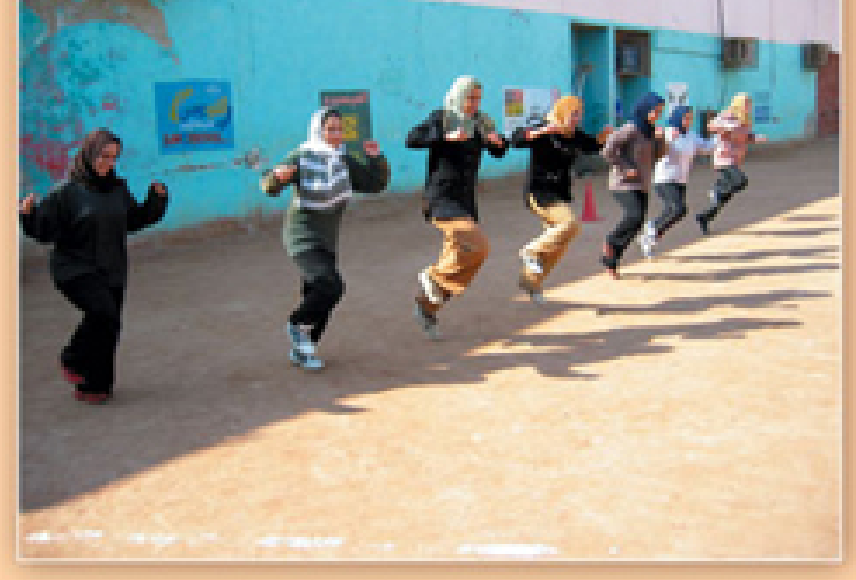

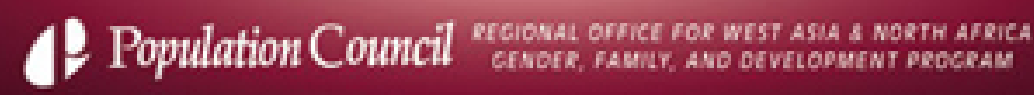

